\title{
Auto-avaliação da atuação da tutoria no curso de licenciatura em pedagogia a distância de uma universidade brasileira
}

\author{
Lilian Schwab Gelatti \\ Universidade Federal do Rio Grande do Sul, Brasil \\ Vânia Ben Premaor \\ Universidade Católica Argentina
}

\begin{abstract}
Resumo
Este artigo relata e analisa a auto-avaliação da atuação de tutores no Curso de Licenciatura em Pedagogia a Distância - PEAD/UFRGS, oferecido por uma universidade brasileira. Buscou-se sondar, mediante um estudo de caso, a função dos tutores no contexto deste curso a distancia, em conformidade com o Guia do Tutor, e aferir se tais procedimentos ensejam melhor aprendizagem.
\end{abstract}

Palavras-chave

Tutoria; Educação a distância; Avaliação

\section{Introdução}

A apresentação do presente trabalho ${ }^{1}$ sobre auto-avaliação da atuação dos tutores no Curso de Licenciatura em Pedagogia (PEAD), na Modalidade de Educação a Distância (EAD), da Faculdade de Educação da Universidade Federal do Rio Grande do Sul (FACED/UFRGS) — situada no município de Porto Alegre, no estado do Rio Grande do Sul (RS/ Brasil) deve-se por sua diferencial proposta de atuação da tutoria diante das inúmeras identidades que esta tem assumido no campo da EAD no âmbito nacional e internacional. 
Este artigo trata dos processos e resultados de uma pesquisa acadêmica sobre a avaliação da atuação dos tutores "presenciais" e os "a distância", sob a sua própria ótica no que se refere as suas funções no Curso PEAD/UFRGS. Objetiva-se investigar essa avaliação do(a) tutor(a) sobre sua atuação no Curso, buscando identificar e analisar a avaliação do tutor no que se refere: a sua prática das concepções e metodologias do Curso; ao seu atendimento aos alunos do Curso; a sua fluência em tecnologia utilizada no Curso. Propõe-se relatar as etapas de desenvolvimento dessa pesquisa, contextualizando sua proposta de investigação e o processo teóricometodológico empregado, contribuindo à comunidade acadêmica da UFRGS e de outras instituições de educação superior.

\section{Contextualização da proposta de investigação}

2.1. Atual conjuntura sócio-educacional: repercussões da e na EAD

Com a democratização do ensino, aumentou a oferta e a demanda pela educação de nível superior. Essa realidade tornou crescente, em muitas universidades, a necessidade de adaptação aos novos desafios de uma sociedade em transformação, afinadas com os avanços científicotecnológicos e concepções sócio-filosóficas do atual milênio. Nesta perspectiva, a educação a distância (EAD), "como estratégia de ampliação das possibilidades de acesso à educação, deve aprofundar o compromisso do pedagógico com o histórico, político e cultural da sociedade" (Gelatti, 2005: 139).

Pela diversidade de políticas e experiências em educação a distância adotadas em instituições de ensino superior, tanto em contextos nacionais como em internacionais, observa-se que há diferentes entendimentos e modos de fazer pedagógicos atribuídos a ambientes virtuais construídos a partir de indicadores que vislumbrem a promoção da aprendizagem, bem como aos demais elementos que podem compor uma determinada proposta de EAD.

Todavia, conceituar a educação a distância é uma tarefa delicada, tendo em vista as várias formas de apresentação encontradas. Nesse sentido, Aretio (1999) menciona que "a dificuldade de definição é universal", pois, 
entre outros aspectos, "existem as instituições duais ou mistas, presencialmente e a distância, que são as formas híbridas de ensino" (p. 42). Para Perkins (2003), a EAD pode ser definida como uma metodologia educativa não-presencial baseada na comunicação pluridirecional mediatizada, a qual "implica possibilidades de participação de estudantes dispersos, com autonomia de tempo, espaço e compromisso na orientação docente, na escolha dos meios, estes adequados para os temas e as possibilidades de acesso dos usuários" (p. 37). No entanto, são visíveis iniciativas de EAD na educação superior que contemplam também ações educativas presenciais, mesmo que em menor quantidade em relação às ações não-presenciais, tais como a sistemática de encontros presenciais entre professores e coordenações, a realização de aulas presenciais e a aplicação de trabalhos e/ou provas finais, sendo esta última um procedimento que busca atender a uma exigência legal no contexto brasileiro. Esse, por exemplo, é o caso do Curso PEAD/UFRGS.

A legislação brasileira da EAD, o Art. $1^{\circ}$ do Decreto $N^{\circ} 5.622$, de 19 de Dezembro de 2005 - que regulamenta o art. 80 da Lei no 9.394, de 20 de Dezembro de 1996, a qual estabelece as diretrizes e bases da educação nacional - define a EAD como uma modalidade educacional "na qual a mediação didático-pedagógica nos processos de ensino e aprendizagem ocorre com a utilização de meios e tecnologias de informação e comunicação, com estudantes e professores desenvolvendo atividades educativas em lugares ou tempos diversos" (Brasil, 2008). Essa definição permite a abertura de uma diversidade de proposições formativas nessa área.

Há, assim, dificuldade de conceituar a educação a distância devido à existência de elementos como, conforme menciona Cruz (2001: 71): 'distância', que tem múltiplos significados; depois, a educação a distância tem sido usada para uma variedade enorme de programas e, finalmente, as rápidas mudanças na tecnologia têm desafiado os meios técnicos tradicionais, sob os quais a educação a distância é definida. Moore e Kearsley adotam a seguinte definição na tentativa de compreender a natureza multidimensional da EAD: "é o aprendizado planejado que ocorre normalmente em um lugar diferente do local do ensino, exigindo técnicas especiais de criação do curso e de instrução, comunicação por meio de várias tecnologias e disposições organizacionais e administrativas especiais" (2008: 2). 
A partir do crescente avanço computacional, conforme Lévy (1993), Ben (2004) e Martínez (1998), surgem novas perspectivas de aplicação no ensino, principalmente através da Internet. Nos tempos atuais, cursos on-line estão sendo introduzidos em instituições de ensino em um ritmo acelerado. No entanto, esses cursos não assumem o papel de substituto do ensino presencial, mas sim de coadjuvante nos processos de ensino e de aprendizagem. Ações formativas pela EAD atingem resultados significativos quando as novas tecnologias da informação e da comunicação (TIC) estão integradas num contexto estrutural de mudança de concepções e práticas tradicionais descontextualizadas acerca do ensino e da aprendizagem, intencionando que professores e alunos vivenciem processos de comunicação mais abertos, de efetiva participação interpessoal e grupal. Caso contrário, a Internet e as hipermídias em geral serão tão somente recursos pedagógicos a mais que reforçarão formas tradicionais de educação, as quais apresentam inconstâncias teórico-práticas diante do atual contexto que vivenciamos. A modalidade de $E A D$, por si só, não modifica os processos de ensinar e de aprender, mas depende de transformações de concepções e práticas diante da vida, do mundo, da sociedade, de si mesmo e da "filosofia real" - não apenas teórica, mas a vivenciada pelas instituições/pessoas. Nesse sentido, Gelatti (2005), considera que "(...) a Educação a Distância, como qualquer forma de educação, não apenas deve 'pretender ser', mas precisa concretamente realizar-se como uma prática social significativa e conseqüente em relação aos princípios filosóficos de uma consistente proposta pedagógica" (p. 140).

O impacto das novas tecnologias de informação e comunicação na proliferação das fontes de informação e nas possibilidades de ensino e aprendizagem à distância é, segundo Santos (2005: 49-50), um dos fatores responsáveis pelo "abalo" da atual universidade pública, resultando na conversão das novas tecnologias em instrumentos pedagógicos. A UFRGS, como instituição de ensino superior (IES) pública e "bi-modal" — isto é, que compreende tanto o ensino presencial como a educação a distância -, encontra-se também dentro desse panorama. As novas tecnologias "são capazes de trazer uma mudança profunda à formação no meio prático, assim como no futuro perfil da prática dos docentes [tutores e alunos] em formação" (Karsenti, 2008: 182). 
Com o crescimento da EAD em IES, como modalidade educacional e subárea de conhecimento a ser amplamente investigada, torna-se ainda mais evidente que a profissão fundamental do presente e do futuro é educar. Educar para saber compreender, comunicar-se e agir melhor, integrando a comunicação pessoal, a comunitária e a tecnológica. Desta forma, desenvolve-se a possibilidade de criar e resolver problemas e instrumentos em novos campos/ situações, criar fontes de novidades (Piaget, 1995: 274286), imprimir significações aos diversos aspectos que compõe o universo do aluno, do tutor e do professor. Nesta perspectiva, a educação a distância como modo de realizar educação deve pressupor, conforme Gelatti, "uma concepção de educação como um processo permanente, em que o saber se faz através de uma superação constante e que concebe tanto os educadores quanto os alunos como aprendizes contínuos, sujeitos de sua própria educação" (2005: 138).

A rapidez das mudanças nos meios de comunicação e suas repercussões nas relações humanas no âmbito sociocultural coloca-nos frente a uma realidade muito pouco explorada, que muda a uma velocidade progressiva e, de certa forma, atemorizadora. Dentro destas mudanças encontramos novas formas de informação e comunicação, as quais nem sempre são utilizadas com perspicácia. Nesta perspectiva, a educação precisa possibilitar mais a compreensão e apropriação das novas tecnologias e linguagens, desvendar os seus códigos, dominar as possibilidades de expressão e os possíveis projetos. A linguagem com seus domínios lingüísticos, por exemplo, se desdobra em reflexões e em tomadas de consciência (Piaget, 1995: 274-286) mediante as quais o ser humano cria o mundo junto com os outros. Ele é um projeto infinito (Boff, 1998).

Nesse contexto, a palavra-chave é integrar a Internet com as outras tecnologias na educação; integrar o mais avançado com as técnicas convencionais, com o humano e o tecnológico, dentro de uma visão pedagógica criativa e aberta. Nas palavras de Moran (2000):

nossa mente é a melhor tecnologia infinitamente superior em complexidade ao melhor computador, porque pensa, relaciona, sente, intui e pode surpreender. O poder de integração não está fundamentalmente nas tecnologias, mas nas nossas mentes (p. 10). 
De acordo com o que afirma Moran (ibidem) e confirma Morin (2001), "pela educação inovadora e integradora desenvolvemos as nossas qualidades, habilidades para realizar-nos e tornar-nos produtivos em todas as dimensões possíveis pessoais e interpessoais". Para que o conhecimento seja pertinente, a educação deverá torná-lo evidente. O conhecimento do conhecimento, que comporta a integração do conhecedor em seu conhecimento, deve ser para a educação um princípio e uma necessidade permanentes.

$A E A D$ deve viabilizar a interação social entre alunos e professores que superam as distâncias sociais e geográficas, possibilitando dispor de espaços para interação, os quais ajudam a fortalecer vínculos cognitivo-afetivos. Ao utilizar ambientes virtuais, a postura dialógica e cooperativa entre os agentes envolvidos no processo é elemento essencial. Faz-se necessário a um curso on-line, segundo Marchand, um "ambiente virtual (...) para as discussões, para a interação, para a negociação e a construção de sentido" (2002: 146), o qual deve permitir a interação constante e on-line entre alunos, tutores, professores e/ou demais partícipes do curso, aproveitando o imenso potencial de atuais meios e recursos eletrônicos de comunicação, a fim de que se possibilite a criação de espaços-tempos coletivos de aprendizagens. Nesse sentido, ao perceberem sua importância no processo, os sujeitos sentem-se responsáveis pelo seu próprio aprendizado e pelo do grupo em que estão inseridos.

Tomando em consideração o breve panorama sócio-educacional apresentado sobre a educação a distância, considera-se que a qualificação dos processos de ensino e de aprendizagem depende, especialmente, do exercício da função do tutor - tendo presente que a relevância da tutoria na EAD não isenta, em absoluto, o professor de sua responsabilidade intransferível pelos processos de planejamento, avaliação, concretização da proposta pedagógica e de todas as funções que compõem o fazer docente. Sendo assim, para que esses processos possam ser qualificados, é necessário que se crie um processo interativo de avaliação, no qual se produza uma retro-alimentação avaliadora e modificadora da atuação do tutor por ele próprio - como também da atuação de todos os agentes envolvidos - com a finalidade de saber se o processo possibilitou a concretização dos objetivos e resultados almejados, e que se introduzam modificações oportunas caso seja necessário. Portanto, este trabalho intenciona contribuir 
para a avaliação, na visão do próprio tutor, de sua atuação no Curso de Licenciatura em Pedagogia a Distância da UFRGS.

\subsection{Auto-avaliação da Tutoria no Curso PEAD/UFRGS: foco do estudo}

A tutoria em Educação a Distância consiste num tema conceitual bastante polêmico e ainda carente de uma fundamentação legislativa que dê suporte administrativo, econômico e educacional e reconhecimento social de sua função no mercado de trabalho. Quando referimo-nos ao "tutor" — ao seu papel, as suas funções, as suas tarefas e responsabilidades, ao seu lugar dentro dos processos de ensino e de aprendizagem na e para a educação a distância - muitos questionamentos surgem diante da diversidade de concepções e práticas que este recurso humano assume nos mais diferentes contextos de EAD: O que se quer dizer com ser "tutor"? Qual é a sua importância na modalidade de educação a distância? Que perfil de tutor é desejado em cursos em EAD? Até onde compreende as suas funções? Que espaços ele ocupa? Qual é a especificidade de seu papel? Que diferenças se elas existem - o seu trabalho apresenta do ser professor em EAD? Como se forma um tutor? Como se avalia a sua produção? Que elementos e estratégias terá um bom projeto de tutoria?

Diante da emergência dessa multiplicidade de questões e desafios, entre outros, ressalta-se que uma das razões para a existência de diferentes concepções e práticas do ser tutor deve-se pelas diversificadas intenções presentes nos projetos político-educacionais de cada País, adotados nas instituições e organizações que promovem a EAD. Avaliar as concepções e práticas da tutoria na EAD de determinada instituição implica, necessariamente, em refletir sobre sua praxis educativa, as diferentes perspectivas educacionais, tendo presente, mais amplamente, sua visão e atuação perante os contextos social, histórico, político, econômico e cultural. Dessa forma, pode-se dizer que "refletir atualmente, na atividade educativa no contexto da 'Sociedade da Informação' é, sobretudo, pensar na adoção de formas de educação aberta, flexível e que considerem a relação tempoespacial, com uma forte vertente de formação ao longo de toda a vida" (Gelatti, 2005: 145). 
Essas diferentes perspectivas educacionais remetem-nos à necessária reflexão sobre os paradigmas orientadores da praxis educativa. Bertrand e Valois (s/d) apontam relações da educação com a sociedade, sendo que a "organização educativa pode, como qualquer outra organização social, contribuir para a modificação das orientações da sociedade", com uma certa autonomia, além de "intervir nas suas próprias orientações, frisadas pela sociedade, quer as aceitando, adaptando-as ou contestando-as" (p.14), sendo que a sociedade "pode impor um novo sentido as suas práticas", pois "o campo político e organizacional não são independentes das orientações do campo paradigmático (...)" (p. 23).

Em decorrência das problematizações levantadas neste artigo, originadas da pesquisa acadêmica em questão, buscou-se refletir sobre a atuação do tutor, valorizando sua auto-avaliação, tomando como contexto uma instituição de ensino superior pública, a qual promove um curso de graduação em Pedagogia na modalidade a distância - iniciado no $2^{\circ}$ semestre de ano de 2006 - para professores em exercício em escolas da rede pública, os quais não dispõem de habilitação superior.

A partir da temática principal a avaliação dos tutores sobre sua atuação no Curso de Licenciatura em Pedagogia a Distância da UFRGS, o estudo apresentado nesse artigo propõe, como objetivo geral, analisar a avaliação do(a) tutor(a) sobre sua atuação no Curso PEAD/UFRGS. Como objetivos específicos, este trabalho buscou identificar e analisar a avaliação do tutor quanto: a) a sua prática das concepções e metodologias do Curso; b) ao seu atendimento aos alunos do Curso; c) a sua fluência em tecnologia utilizada no Curso. Com base nesse contexto, levantou-se a seguinte questão-problema: Qual é a avaliação do(a) tutor(a) do Curso PEAD/UFRGS quanto ao seu atendimento aos alunos, a sua fluência na telemática/tecnologia e a sua prática das concepções e metodologias do Curso?

A seguir, apresenta-se a proposta metodológica que orientou a análise da auto-avaliação da atuação de tutores no Curso de Licenciatura em Pedagogia a Distância — PEAD/UFRGS e, na seqüência, os resultados dessa análise propriamente dita. 


\section{Trajetória metodológica}

Como delineamento deste estudo, teve-se como foco a análise da avaliação que o(a) tutor(a) faz de sua atuação no Curso PEAD/UFRGS. Optou-se por um estudo de caso, com abordagem metodológica de cunho qualitativo, pois, segundo Bardin, a abordagem qualitativa "corresponde a um procedimento mais intuitivo, mas também mais maleável e mais adaptável a índices não previstos, ou a evolução das hipóteses" (1977: 115).

Como contexto de investigação, foi escolhido o Pólo de Sapiranga do Curso PEAD/UFRGS, localizado no município de Sapiranga (RS/Brasil), devido à proximidade de uma das pesquisadoras, autora desse artigo, com esse Pólo, por ser professora do Curso. Já como sujeitos participantes, esta pesquisa abarcou: dois Tutores do Pólo (os 'presenciais', que no geral atuam no mesmo espaço físico que os alunos, permitindo o contato humano direto) e cinco Tutores da Sede (os 'a distância', que atuam mais por meio do ciberespaço do que no mesmo espaço físico que os alunos) do Pólo de Sapiranga, sendo os últimos pertencentes às interdisciplinas (desenvolvidas no $2^{\circ}$ semestre do ano de 2006, correspondente ao primeiro eixo articulador — organizador do semestre letivo — do Curso): Seminário Integrador; Escola, Projeto Pedagógico e Currículo; Escola, Cultura e Sociedade; Educação e Tecnologias da Comunicação e da Informação. Foi utilizada a seguinte legenda de identificação dos sujeitos participantes dessa pesquisa:

$\begin{array}{ll}\text { Sujeitos } & \text { Símbolo } \\ \text { Tutor (Pólo e Sede) } & \text { T1, T2, T3... } \\ \text { Tutor do Pólo } & \text { TP1, TP2 ... } \\ \text { Tutor da Sede } & \text { TS1, TS2 .. }\end{array}$

Como procedimentos de coleta de dados, o instrumento de pesquisa utilizado neste estudo emergiu do instrumento de avaliação dos tutores elaborado pela Coordenação do Curso PEAD/UFRGS. Este último instrumento consistiu em um questionário com questões semi-estruturadas a serem respondidas por escrito, disponibilizado de forma on-line aos tutores.

A Coordenação do Curso apresentou aos tutores o instrumento de avaliação no encontro presencial ocorrido no mês de Dezembro de 2006. 
Neste encontro, a Coordenação buscou fazer combinações com a tutoria da sede e a do pólo dos cinco Pólos do Curso - Pólo de Alvorada, Gravataí, Sapiranga, São Leopoldo e o de Três Cachoeiras (RS/Brasil) -, flexibilizando prazos e formas de preenchimento do instrumento, de acordo com as solicitações dos tutores presentes, mas sem perder de vista os objetivos da proposta da aplicação. Também foi oportunizado um momento para que os tutores pudessem analisar a estrutura do instrumento de pesquisa e propor alterações neste que fossem necessárias, a fim de que este instrumento se adequasse às diversidades do público em questão.

Após as devidas alterações efetuadas nos instrumentos por parte da Coordenação do Curso, com a finalidade de contemplarem as sugestões propostas pelos tutores, os instrumentos foram publicados em Pbwik? (ficando acessíveis pelo site: http://avaliacao.pbwiki.com), que é o WIKI utilizado no PEAD, e a senha disponibilizada aos tutores para que realizassem o preenchimento do instrumento.

Além do preenchimento dos instrumentos de avaliação por cada tutor(a), a proposta de avaliação da Coordenação do Curso também incluiu a avaliação de cada tutor por seu colega tutor (no instrumento de avaliação consta "Tutor-Avaliador 1"), bem como a avaliação do tutor pelo professor do Curso ("Professor-Avaliador"). Nesta pesquisa, devido aos seus objetivos, apenas foi considerado o primeiro momento avaliativo, proposto pela Coordenação como corpo de análise, ou seja, o preenchimento dos instrumentos de avaliação por cada tutor.

O instrumento de avaliação proposto aos tutores comportou categorias e indicadores. Por categoria compreende-se atributos que exprimem conceitos entre diversas relações entre idéias ou fatos. Ela possui indicadores, sendo estes proposições explicativas relacionadas às categorias. A partir disso, a proposta de avaliação da Coordenação do Curso abrangeu as seguintes relações como coleta de dados: Categoria $A$ : Prática das concepções e metodologias do PEAD; Categoria B: Atendimento aos alunos; Categoria $C$ : Interações com professores e tutores; Categoria $D$ : Fluência na telemática/tecnologia; Categoria E: Atitude profissional.

Já nesta pesquisa foram consideradas para análise de dados apenas as categorias $A, B$ e $D$, cada uma com diferentes indicadores, sendo estes elaborados a partir das funções dos tutores da sede e do pólo. Devido as 
especificidades de suas funções, o instrumento dos tutores do pólo foi distinto do instrumento dos tutores da sede. Deste modo, é possível analisar as ações dos tutores 'a distância' e os 'presenciais' segundo sua própria auto-avaliação, objetivando a contínua qualificação de sua 'competência'.

Com relação aos indicadores, esta pesquisa considerou:

\section{- Quanto à Categoria A: Prática das concepções e metodologias do PEAD}

a) Indicadores para o Tutor do Pólo: 1. Promoção da construção de uma comunidade de aprendizagem; 2. Valorização das experiências dos alunos e os saberes constituídos na prática; 3. Uso de procedimentos baseados na metodologia do curso para orientar o feedback aos alunos ao promover o desequilíbrio das certezas; 4. Estímulo ao uso crítico das tecnologias; 5 . Estímulo à permanência dos alunos no curso; 6 . Alimentação sistemática do diário de bordo.

b) Indicadores para o Tutor da Sede: 1 . Promoção da construção de uma comunidade de aprendizagem; 2. Valorização das experiências dos alunos e os saberes constituídos na prática; 3. Análise crítica de produções apresentadas no ambiente virtual; 4 . Uso de procedimentos baseados na metodologia do curso para orientar o feedback aos alunos ao promover o desequilíbrio das certezas; 5 . Conhecimento e reflexão sobre conceitos e conteúdos trabalhados; 6 . Estímulo ao uso crítico das tecnologias; 7. Estímulo à permanência dos alunos no curso; 8. Alimentação sistemática do diário de bordo.

\section{- Quanto à Categoria B: Atendimento aos alunos}

a) Indicadores para o Tutor do Pólo: 1. Prontidão para atender aos alunos; 2. Intervenção visando à reflexão, à informação e ao incentivo através de: a) Carga-horária (20h) regular de atendimento aos alunos no pólo; b) Organização e sistematização no atendimento ao aluno; c) Resposta aos e-mails dos alunos. 
b) Indicadores para o Tutor da Sede: 1. Prontidão para atender aos alunos; 2. Intervenção visando à reflexão, à informação e ao incentivo através de: a) Resposta aos e-mails dos alunos; b) Manifestação em fóruns dos alunos; c) Comentários nos webfólios; d) Comentários nos blogs; e) Comentários nos diários de bordo dos alunos; 3. Horário de chat para atendimento aos alunos.

\section{- Quanto à Categoria D: Fluência na telemática/tecnologia}

a) Indicadores para o Tutor do Pólo e Tutor da Sede: 1. Ambiente ROODA; 2. Pbwiki; 3. Blog; 4. Provedores de serviço tais como: BubbleShare, You Tube, etc. 5. Editor de texto; 6. Editor de apresentação; 7. Editor de imagens; 8. Editor de página; 9. Ferramentas de mensagem instantânea.

Convém salientar que o instrumento de avaliação dos e pelos tutores, proposto pela Coordenação do Curso, considerou a indicação por parte do tutor de evidências e fontes para cada indicador, nas quais ele teve que comprovar, por meio de recortes de seus registros de atuação no Curso, consistência qualitativa do trabalho, a qual desenvolveu ao longo do semestre. Além disso, o instrumento também solicitou a avaliação do tutor sobre cada uma das categorias de análise.

Como procedimentos de análise de dados, esta pesquisa optou pelo estudo de caso, pois a preocupação central das pesquisadoras focou mais o ato de compreender do que explicar o objeto de estudo. Compreender é tomar o objeto na sua intenção total e perceber o modo peculiar e específico de o objeto existir; logo, a compreensão necessitará da meta-compreensão dos significados, que se constituirá numa interpretação. O estudo de caso, segundo Rauen (2002), diz respeito à interpretação de um contexto, isto é, para uma apreensão mais completa do objeto é preciso levar em conta o contexto em que ele se situa. O contexto representa o Curso em estudo, tendo em vista a questão-problema norteadora.

Como etapas do procedimento de análise, primeiramente foram selecionadas as respostas dos tutores participantes deste estudo, tendo em vista os procedimentos de coleta de dados. Em seguida, foi analisado o corpo textual e selecionadas as respostas que estavam relacionadas à categoria e 
ao seu respectivo indicador. Destas, colheu-se as partes relevantes dentro da problemática deste estudo, possibilitando a organização de quadros com o intuito de melhor organizar a análise e apresentar, em cada categoria, a opinião do tutor, com sua avaliação sobre a mesma. Também foram organizados os quadros 1-Tutores do Pólo e 2-Tutores da Sede, apresentados a seguir, nos quais é possível visualizar a participação dos tutores quanto ao preenchimento do instrumento de avaliação, referente à resposta ou não aos indicadores de cada categoria do questionário, como dado contributivo à pesquisa realizada. Após, os dados foram descritos no formato de um corpo textual para o desenvolvimento posterior do processo de interpretação. Os resultados obtidos foram analisados à luz do Guia do Tutor (Carvalho; Nevado; Bordas, 2006) e de referenciais teóricos que vão ao encontro da proposta pedagógica do Curso.

\section{Levantamentos da participação dos Tutores quanto ao preenchimento do Questionário}

Quadro 1 - Tutores do Pólo (TP)

\begin{tabular}{|c|c|c|c|c|c|c|}
\hline Categorias & Categoria A & $\begin{array}{c}\text { Tutores que } \\
\text { responderam } \\
\text { aos } \\
\text { indicadores } \\
\text { da Categoria } \\
\text { A }\end{array}$ & Categoria B & $\begin{array}{c}\text { Tutores que } \\
\text { responderam } \\
\text { aos } \\
\text { indicadores } \\
\text { da Categoria } \\
B\end{array}$ & Categoria D & $\begin{array}{c}\text { Tutores que } \\
\text { responderam } \\
\text { aos } \\
\text { indicadores } \\
\text { da Categoria D }\end{array}$ \\
\hline \multirow{8}{*}{ Indicadores } & $\begin{array}{l}\text { Indicador } 1 \\
\text { Indicador } 2\end{array}$ & $\begin{array}{l}\mathrm{T} 1 ; \mathrm{T} 2 \\
\mathrm{~T} 1 ; \mathrm{T} 2\end{array}$ & $\begin{array}{c}\text { Indicador } 1 \\
\text { Indicador } \\
2 a\end{array}$ & $\begin{array}{l}\text { T1; T2 } \\
\text { T1; T2 }\end{array}$ & $\begin{array}{l}\text { Indicador } 1 \\
\text { Indicador } 2\end{array}$ & $\begin{array}{l}\text { T1; T2 } \\
\text { T1; T2 }\end{array}$ \\
\hline & Indicador 3 & T1; T2 & $\begin{array}{c}\text { Indicador } \\
2 \mathrm{~b}\end{array}$ & $\mathrm{~T} 1 ; \mathrm{T} 2$ & Indicador 3 & $\mathrm{~T} 1 ; \mathrm{T} 2$ \\
\hline & Indicador 4 & T1; T2 & $\begin{array}{c}\text { Indicador } \\
2 \mathrm{c}\end{array}$ & T1; T2 & Indicador 4 & T1; T2 \\
\hline & Indicador 5 & $\mathrm{~T} 1 ; \mathrm{T} 2$ & - & --- & Indicador 5 & T1; T2 \\
\hline & Indicador 6 & T1; T2 & --- & --- & Indicador 6 & $\mathrm{~T} 1 ; \mathrm{T} 2$ \\
\hline & --- & --- & --- & --- & Indicador 7 & T1; T2 \\
\hline & --- & --- & --- & --- & Indicador 8 & T1; T2 \\
\hline & --- & --- & --- & --- & Indicador 9 & T1; T2 \\
\hline
\end{tabular}


Quadro 2 - Tutores da Sede (TS)

\begin{tabular}{|c|c|c|c|c|c|c|}
\hline Categorias & Categoria A & $\begin{array}{c}\text { Tutores que } \\
\text { responderam } \\
\text { aos } \\
\text { indicadores } \\
\text { da Categoria } \\
\text { A } \\
\end{array}$ & Categoria B & $\begin{array}{c}\text { Tutores que } \\
\text { responderam } \\
\text { aos } \\
\text { indicadores } \\
\text { da Categoria } \\
B \\
\end{array}$ & Categoria D & $\begin{array}{c}\text { Tutores que } \\
\text { responderam } \\
\text { aos } \\
\text { indicadores } \\
\text { da Categoria D }\end{array}$ \\
\hline \multirow{9}{*}{ Indicadores } & Indicador 1 & T1; T3; T4; T5 & Indicador 1 & T1; T3;T5 & Indicador 1 & $\begin{array}{c}\text { T1; T2: T3; T4; } \\
\text { T5 }\end{array}$ \\
\hline & Indicador 2 & T1; T3; T4; T5 & $\begin{array}{c}\text { Indicador } \\
\mathbf{2 a}\end{array}$ & T1; T3; T5 & Indicador 2 & T1; T2: T3; T5 \\
\hline & Indicador 3 & T1; T3; T4; T5 & $\begin{array}{c}\text { Indicador } \\
\mathbf{2 b}\end{array}$ & T1; T3;T5 & Indicador 3 & $\begin{array}{c}\text { T1; T2; T3 T4; } \\
\text { T5 } \\
\end{array}$ \\
\hline & Indicador 4 & T1; T3; T4 & $\begin{array}{c}\text { Indicador } \\
\text { 2c }\end{array}$ & T1; T3; T5 & Indicador 4 & T1; T2; T3;T5 \\
\hline & Indicador 5 & T1; T3; T4; T5 & $\begin{array}{l}\text { Indicador } \\
\text { 2d }\end{array}$ & T1; T3; T5 & Indicador 5 & T1; T2; T3;T5 \\
\hline & Indicador 6 & T1; T3; T4; T5 & $\begin{array}{c}\text { Indicador } \\
2 \mathrm{e}\end{array}$ & T1; T5 & Indicador 6 & T1; T2; T3;T5 \\
\hline & Indicador 7 & T1; T3; T4; T5 & Indicad or 3 & T1; T3; T5 & Indicador 7 & T1; T2; T3;T5 \\
\hline & Indicador 8 & T1; T3; T4; T5 & --- & --- & Indicador 8 & T1; T2; T3; T5 \\
\hline & --- & --- & --- & --- & Indicador 9 & T1; T2; T3;T5 \\
\hline
\end{tabular}

Por fim, as pesquisadoras pretenderam fazer a devolução dos resultados da análise dos dados aos sujeitos de pesquisa por meio da publicação deste artigo, pois uma das etapas imprescindíveis da pesquisa é o momento da divulgação de seus resultados. Com relação a isso, Moraes aponta-nos que "mesmo conscientes de que a verdadeira compreensão seguidamente só é acessível a quem se envolveu no processo da pesquisa, é importante ampliar o grupo dos que tomam conhecimento das novas verdades" (2002: 20).

\section{Discussão dos dados e resultados}

A partir de quadros de análise de dados, conforme exposto na trajetória metodológica, apresenta-se o presente tópico de descrição e discussão dos dados e análise dos resultados correspondentes à avaliação dos tutores sobre a sua atuação no Curso PEAD/UFRGS.

\subsection{Categoria A: Prática das concepções e metodologias do PEAD}

Quanto aos Tutores do Pólo, com relação aos indicadores da Categoria A, foi levantado: a) a promoção da construção de uma comunidade de aprendizagem se dá naturalmente com as trocas de idéias, com a construção coletiva do saber, ocorrendo freqüentemente no Pólo por meio das 
aulas presenciais e on-line; b) a importância do reconhecimento do saber trazido pelos alunos e de cada nova aprendizagem, dos seus questionamentos surgidos a partir da prática em sala de aula, da resignificação de conceitos da prática nos momentos anteriores e posteriores ao aprofundamento teórico; c) a necessidade de valorização das tarefas realizadas, de reflexão sobre as mesmas; d) a existência, por vezes, de uma preocupação maior com a postagem de atividades do que com o feedback (retorno avaliativo); e) o uso de procedimentos baseados na metodologia do Curso para orientar o feedback aos alunos e promover o desequilíbrio das certezas; f) a importância da realização de comentários avaliativos em relação aos trabalhos dos alunos que incitem a postura crítica frente às tecnologias; g) a promoção da permanência de alunos no Curso é realizada através de contatos via e-mail, por telefone e, em algumas situações, presenciais. Quanto a isso foi destacado que o Pólo de Sapiranga possui alunos de diversos municípios próximos ao de Sapiranga (RS/Brasil), e que alguns deles desistiram do Curso pelo fato de não terem como se deslocar até o Pólo devido a dificuldades relacionadas à distância entre sua moradia e o Pólo e ao turno noturno para o deslocamento de ônibus (transporte coletivo) de seu município ao Pólo; de não terem computador em casa ou, ainda, no caso de o possuírem, não disporem de banda larga.

Também foi levantado pelos tutores do pólo, quanto a essa categoria, que ainda não há o hábito da alimentação sistemática da ferramenta de comunicação diário de bordo ${ }^{3}$ por parte deles, porém reconhece-se a importância em fazê-lo; há necessidade da realização de auxílio tecnológico com relação aos alunos, pois a maioria dos que freqüentam o Pólo não tem domínio total da tecnologia utilizada na realização das atividades.

Já com relação aos Tutores da Sede, quanto aos indicadores da Categoria A, foi apontado que: a) foram promovidas várias interações entre alunos nos chats e nos blogs, objetivando a construção de comunidades de aprendizagem, e o acompanhamento sistemático deles por meio dos blogs e diários de bordo; b) foram possibilitadas propostas de trabalho que intencionaram a construção de conhecimentos elaborados, aliada a intervenções pedagógicas, a criação e a participação em fóruns para o debate de temáticas, enfatizando a valorização das experiências dos alunos e dos saberes constituídos na prática; c) foram realizados debates via e-mail, bate- 
papos e software $M S N$, bem como análises das produções dos alunos, apresentadas no ambiente virtual de forma crítica e flexível; d) também, a provocação do interesse dos alunos em relação à auto-gestão de suas aprendizagens, auxiliando-os no que se refere ao uso dos recursos tecnológicos; e) quanto ao indicador relativo ao conhecimento e reflexão sobre conceitos e conteúdos trabalhados, houve o relato de que o tutor e o professor na realidade não "transmitem" conhecimentos para os alunos, mas elaboram pontes conectivas necessárias para a construção deste conhecimento, sendo que refletir, avaliar, interagir, opinar e incentivar fazem parte destas conexões; f) há necessidade de uma formação integral (no que se refere ao conjunto de interdisciplinas, às atividades, aos encontros, etc.) como incentivo ao uso crítico da tecnologia; g) considera-se importante o envio constante de e-mail aos alunos, mobilizando-os a permanecer constantemente no Curso; h) promove-se a realização de registros diários ou semanais das atividades nos diários de bordo, além do uso de blogs e e-mails para o relato de atividades realizadas.

No que diz respeito aos indicadores da Categoria A, percebeu-se, por meio dos depoimentos dos Tutores do Pólo e dos da Sede, a partir dos dados levantados, que tanto os tutores do pólo quanto os da sede avaliam que a sua prática referente às concepções e metodologias do Curso PEAD/UFRGS é concretizada no fazer diário do Curso. Salientam-se alguns depoimentos que confirmam essa avaliação:

Durante este semestre concentrei minha atenção no auxílio às alunas no uso da ferramenta tecnológica necessária ao sucesso do curso, bem como atender, de forma instigadora, às dúvidas nas produções das meninas. Também sofri com as angústias, desesperos e me alegrei com as superações das dificuldades. Embora tenha lançado mão de todas as formas de comunicação ao meu alcance para resgatar alunas desistentes, não fui feliz nesta empreitada, pois perdi, ao longo do semestre, nove alunas, ou por motivos particulares ou mesmo por dificuldades de locomoção até o pólo (as que não têm computador ou Internet) (...). (TP2)

Considero também que a disponibilidade para o diálogo por parte do professor (...) possibilitou que pudéssemos estar constantemente questionando as intervenções e pensando formas de aprimorá-las. (TS1)

Em uma análise mais ampla dos relatos dos Tutores da Sede e dos do Pólo relativos a essa categoria, pode-se dizer que eles confirmam diretrizes básicas apresentadas no Guia do Tutor (2006), referencial norteador da 
atuação do tutor no Curso, tal como no que diz respeito à importância da construção efetiva de uma comunidade virtual de aprendizagem como metodologia de EAD. Neste referencial, tal como foi abordado em relatos dos tutores, é orientado ao tutor, como apoio docente, que, como uma de suas atribuições, faça comentários avaliativos referentes aos trabalhos realizados pelos alunos e intermedeie, quando necessário, as relações entre os estudantes e a coordenação do Curso, entre outras (p. 24).

Pallof e Pratt (2002), autores estes contemplados no embasamento teórico do Guia do Tutor (2006), identificam uma comunidade virtual de aprendizagem como agregações culturais que emergem quando um número suficiente de pessoas encontra-se no ciberespaço. Segundo Shaeffer e Anunden (apud Pallof \& Pratt, 2002: 50), uma comunidade pode ser definida como um todo dinâmico interdependente que emerge quando um grupo de pessoas compartilha determinadas práticas, toma decisões em conjunto, identifica-se com algo maior do que o somatório de suas relações individuais e estabelece um compromisso de longo prazo com o bem-estar (o seu, o dos outros e o do grupo em todas as suas inter-relações).

O Guia do Tutor (2006) e alguns dos depoimentos dos tutores salientam a necessidade da promoção do trânsito constante entre a teoria e a prática, pois não existe prática sem teoria e, tampouco, teoria sem prática. 0 equívoco da defesa da dicotomia entre teoria e prática "faz com que se possa imaginar a formação como um espaço teórico e a ação como um espaço prático e, assim, tratados separadamente, elimina-se a possibilidade de atingir o objetivo da formação que é melhorar a qualidade da prática" (Gadotti \& Romão, 2003: 81-82).

A partir disso, pelos dados analisados, evidenciou-se que a prática das concepções e metodologias do PEAD pelo tutor requer o exame de suas próprias visões e atuações educacionais, pois o Curso defende uma proposta pedagógica que apresenta um determinado entendimento de ser humano, sociedade e mundo, de ser profissional da educação, de ser tutor (Gelatti, 2007: 6-7). Nesse sentido, conforme Gelatti:

É nosso engano supervalorizar os recursos tecno-educacionais se os professores, os alunos e demais partícipes transitam em uma práxis educativa amparada por um modelo educacional que não corresponde à proposta pedagógica almejada, acreditando-se que somente a inserção desses recursos no âmbito educacional possibilitará rupturas epistemológicas e paradigmáticas e a concretização da desejada inovação pedagógica. (2007: 6) 
É indispensável, assim, o fomento de espaços formativos voltados a oportunizar a articulação permanente entre a prática e a teoria, a reflexão crítica dos fundamentos educacionais. Vislumbra-se, com isso, que a teoria possa ser discutida e compreendida na - e com a aplicação direta da prática.

\subsection{Categoria B: Atendimento aos alunos}

Quanto aos Tutores do Pólo, com relação aos indicadores da Categoria B, foi levantada: a) a importância do tutor estar preparado para atender aos alunos o mais rapidamente e da melhor forma possível, tanto por meio de contatos virtuais como de presenciais; b) a relevância da promoção de ações mobilizadoras e sugestivas no que se refere à intervenção do tutor quanto às atividades desenvolvidas pelos alunos, oportunizando espaços de reflexão crítica a eles; c) a possibilidade de apoio do grupo de tutoria aos alunos em período integral (com relação à carga-horária regular de atendimento aos alunos no pólo); d) a existência de organização e sistematização no atendimento tutorial oferecido ao aluno.

Já com relação aos Tutores da Sede, referente aos indicadores da Categoria B, foi apontado(a): a) a existência da utilização corrente de e-mails, telefone e Messenger para atender às dúvidas dos alunos; b) a necessidade de centralização do atendimento ao aluno num único ambiente virtual - no caso, o ROODA 4 ; ) a importância da resposta rápida aos e-mails dos alunos; d) a efetuação de leitura das mensagens enviadas pelos alunos nos fóruns; e) em alguns casos, não foram utilizados comentários nos webfólios ${ }^{5}$ devido às atividades dos alunos terem sido postadas/enviadas por eles em outros ambientes virtuais utilizados no Curso; f) também não foram realizados por alguns tutores comentários avaliativos nos blogs, pois as atividades estavam centradas (e eram propostas) em outros ambientes virtuais; g) foram realizados comentários nos diários de bordo dos alunos por eles mesmos após práticas de intervenção pedagógica realizadas por tutores e professores; h) os chats, realizados pelos tutores para o atendimento de alunos, foram agendados em combinação com os últimos para que possibilitassem a participação de todos, principalmente no início do Curso. 
Quanto a esta categoria, foi destacado ainda por um dos tutores da sede, nos depoimentos coletados, que a palavra 'tutor' indica ter responsabilidade por aquele que se deve apoiar/auxiliar/representar, referindo-se, principalmente, aos alunos. Também foi apontado por tutores da sede que a disposição para atender aos alunos é proporcional à vontade de se abrir caminhos para a construção da aprendizagem.

Pelos depoimentos dos Tutores da Sede e do Pólo, no que se refere aos indicadores da Categoria $B$, percebeu-se que o papel do tutor é imprescindível para o desenvolvimento do Curso, tendo em vista a necessidade de sua atuação ser cada vez mais ativa, participativa, comprometida e interventora nos processos de ensino e de aprendizagem. A partir dos dados levantados, evidencia-se que tanto os tutores do pólo quanto os da sede avaliam que o atendimento que realizam aos alunos é uma das ações prioritárias em sua atuação no Curso. Destacam-se alguns depoimentos que confirmam essa avaliação:

Sobre essa categoria, creio que ela é a parte mais básica da função do tutor, que é justamente essa disponibilidade para auxiliar, tirar dúvidas, dar esclarecimentos. (...) Comentei praticamente todas as postagens das alunas no diário de bordo. Utilizei esse espaço tanto para tirar dúvidas quanto para dar palavras de apoio e estímulo, além de tirar dúvidas. Respondi também a todos os e-mails que recebi. (TS4)

Tenho consciência que minha prática, enquanto tutora, foi comprometida com a aprendizagem dentro da concepção do curso. Sempre estive disponível para auxiliar as alunas, tutores/sede e professores. (TP2)

Os depoimentos dos Tutores do Pólo e os da Sede confirmam orientações apresentadas no Guia do Tutor (2006) no que diz respeito às funções pedagógica, social e organizativa dos Tutores da Sede e do Pólo referentes ao atendimento aos alunos, pois suas funções reforçam a necessidade de realizar um rápido, regular e permanente feedback aos alunos e aos demais integrantes da equipe do Curso. Nesse sentido, do ponto de vista da avaliação da aprendizagem, é relevante destacar ainda que o atendimento ao aluno "deve considerar seu ritmo e ajudá-lo a desenvolver graus mais complexos de competências cognitivas, habilidades e atitudes, possibilitando-Ihe alcançar os objetivos propostos" (Filho, 2003: 157).

De acordo com os dados analisados e o indicado no Guia, as funções dos tutores implicam no estabelecimento e fortalecimento de vínculos com 
cada aluno, chamando-os para estarem presentes no ambiente on-line e nos encontros presenciais (estes relativos aos contatos físicos humanos), contribuindo significantemente para a sua permanência qualitativa no Curso e demonstrando prontidão para a realização de contatos com alunos, tutores, professores e coordenação do eixo e geral (2006: 26-27).

Tendo em vista os relatos dos tutores sobre a categoria em questão, nota-se que um importante aspecto a ser salientado a partir da avaliação elaborada por eles de sua própria prática consiste na relevância da intermediação pedagógica como fator singular para a qualificação dos processos de ensino e de aprendizagem. Quanto a isso, conforme Litwin (2001: 21), do ponto de vista do ensino, os tutores fomentam o intercâmbio entre os alunos e concebem atividades complementares que favorecem o estudo de uma perspectiva mais ampla ou integradora.

Outrossim, segundo os depoimentos dos Tutores da Sede, para o atendimento integral da proposta apresentada no Guia do Tutor é necessário que ocorram em maior intensidade intervenções pedagógicas "diretas, com a anuência da equipe, nas atividades realizadas e registradas no webfólio educacional", além da análise qualitativa das produções enviadas no webfólio pelos alunos a partir das proposições das interdisciplinas, bem como "trabalhar a partir da 'pedagogia da pergunta' [um dos conceitos-chave da teoria freireana (Freire, Faundez, 1985)] — propor perguntas que ajudem os alunos a descobrir possíveis contradições ou inconstâncias em suas contribuições nos fóruns e webfólio" (2006: 27). Nessa perspectiva, os tutores precisam desenvolver "competências" pedagógicas, comunicativas e tecnológicas específicas para a EAD em seu perfil profissional.

\subsection{Categoria D: Fluência em Telemática/Tecnologia}

Quanto aos Tutores do Pólo, com relação aos indicadores da Categoria $D$, foi apontado que: a) os tutores apresentaram familiaridade no que se refere ao uso do ambiente virtual ROODA; b) o Pbwiki foi bastante utilizado no início do semestre, porém, em relação a essa ferramenta, houve algumas dificuldades de uso referentes à inserção de arquivos de imagens; c) - Blog pode ser um bom recurso tecnológico-educacional, sendo também utilizado ao longo do Curso; d) não foram utilizados provedores de serviço; e) 
a utilização de recursos do software openoffice livre (Linux), como o editor de texto e o de apresentação; f) a utilização do aplicativo Paint como editor de imagens, do software NVU para a construção de páginas pessoais na Web e do chat do ROODA, bem como do Messenger e A2 ${ }^{6}$, como ferramentas de mensagem instantânea.

Já quanto aos Tutores da Sede, com relação aos indicadores da Categoria D, foi apontada: a) a existência de questionamentos devido à utilização do ambiente virtual ROODA no contexto do Curso, embora tenham sido levantadas evidências favoráveis ao uso desse ambiente quanto à fluência e ao domínio do mesmo pelos partícipes; b) o uso e o conhecimento de como utilizar o Pbwiki, pois foi com esta ferramenta que os tutores iniciaram suas interações com os alunos do Curso - cada Pólo criou o seu Wiki, no qual houve a apresentação dos alunos e das interdisciplinas; c) o recurso Blog foi sinalado pelos tutores como sendo pouco utilizado no Curso, bem como os provedores de serviço; d) o domínio e uso dos editores de texto word do Windows e openoffice do sistema Linux; e) a facilidade de manuseio do editor de apresentação power point do Windows; f) a familiaridade com editores de imagens; g) a utilização no Curso de editor de páginas para publicação na Web (tal como o software NVU), de softwares ou recursos informatizados como o Messenger, Chat do Gmail, A2, ROODA, Skype.

No que se refere aos indicadores da Categoria $D$, percebeu-se muita proximidade entre os depoimentos dos Tutores do Pólo e Sede. Ambos apontaram o domínio com relação ao ambiente virtual oficial do Curso $(R O O D A)$, a utilização de editores de texto, de apresentação, de imagens e de página Web, bem como de ferramentas de comunicação instantânea (síncronas). Também indicaram que houve pouca ou nenhuma utilização de provedores em serviço. Chama a atenção o fato dos Tutores do Pólo terem valorizado mais a utilização dos blogs do que os Tutores da Sede. Isso, possivelmente, tem relação com o fato dos primeiros terem participado mais diretamente, junto aos alunos, dos encontros de formação em telemática/tecnologia realizados principalmente no início do Curso, nos quais se trabalhou o uso de blogs. Pelos dados levantados, percebe-se que os tutores do pólo e os da sede avaliam a fluência da telemática/tecnologia em sua atuação como um dos grandes aprendizados proporcionados pelo vivenciar do Curso: 
Este semestre também foi de grande aprendizado para mim, pois aprendi a utilizar recursos que não tinha nenhum conhecimento e aprimorei o uso de outros que já eram de uso cotidiano. (TS1)

De um modo geral, em relação às ferramentas (...), como qualquer objeto de aprendizagem, estou me familiarizando de modo mais preciso. (TS2)

Através das discussões, interações e trocas ficamos mais alfabetizados tecnologicamente, pois há preocupação com a preparação para atender. (TS3)

Não lembro, em minha vida, de ter aprendido tanto em tão pouco tempo. Hoje me sinto vitoriosa por fazer parte da família PEAD e por saber que vou aprender muito mais. (TP2)

Os depoimentos dos Tutores do Pólo e dos da Sede confirmam o apresentado no Guia do Tutor (2006) no que diz respeito à importância da alfabetização tecnológica. Nesse Guia é informado que como fonte principal de comunicação entre alunos, tutores e professores - além dos encontros presenciais - tem-se a utilização de ambientes e ferramentas virtuais, o uso da Internet, correio eletrônico, listas de discussão, fóruns, chats, entre outros (p. 23).

De acordo com esta perspectiva, coerentemente com o proposto no Guia do Tutor (2006: 23-24), atribui-se aos tutores a atuação nos Pólos e na Sede (FACED/UFRGS) apoiando o trabalho dos professores e dos alunos do Curso, sendo formados para o uso de uma metodologia interativa e problematizadora, bem como para a aplicação de conhecimentos relativos à área de informática na educação e à dinâmica de grupo.

Na modalidade de educação a distância, segundo o referido Guia, o tutor deverá estar preparado para estabelecer interações efetivas via ambientes virtuais e transitar nos demais recursos informatizados propostos no Curso; utilizar os serviços de Internet (tais como, o correio eletrônico, listas de discussão, fóruns de debate, ferramentas de comunicação síncrona) e, ao mesmo tempo, produzir e organizar repositório de produtos, relatórios de experiências, webfólios educacionais de avaliação formativa e continuada, entre outros, caracterizando a importância de aprender sobre a tecnologia, como utilizar os recursos tecnológicos em favor da educação.

É importante frisar que a fluência em telemática/tecnologia no Curso PEAD/UFRGS requer trânsito coerente entre teoria e prática. Dessa forma, essa fluência implica, tal como o exposto nas reflexões sobre a Categoria $A$, em clareza epistemológica sobre as teorias que podem sustentar as 
diferentes formas de conceber e utilizar as tecnologias no âmbito educacional na análise profunda da proposta, estrutura e funcionamento do Curso e dos papéis e funções de seus múltiplos profissionais, entre outros aspectos (Gelatti, 2007: 5).

\subsection{Algumas ponderações pertinentes à análise dos dados}

Faz-se necessário assinalar que alguns dos tutores da sede, que se encontram entre os participantes da pesquisa, não responderam a um ou mais dos indicadores propostos no instrumento avaliativo do Curso. Os quadros 1-Tutores do Pólo e 2-Tutores da Sede demonstraram ainda que um dos tutores da sede respondeu somente aos indicadores pertencentes à categoria D. Isso pode ser explicado pela peculiaridade das ações exercidas por cada tutor no Curso. É preciso considerar ainda que essa proposta de preenchimento do instrumento avaliativo não foi atendida por todos os tutores no prazo indicado pela Coordenação. Por ser um instrumento em que o tutor que o preencheu poderá ser identificado por outros partícipes do Curso por estar publicado no Pbwiki, é possível que alguns tutores tenham se sentido inibidos em apresentar inteiramente o seu posicionamento frente à avaliação de sua própria atuação, embora seja promovida no Curso abertura para a exposição de impressões avaliativas por parte de seus integrantes ao longo dos eixos articuladores. Esses são alguns fatores a serem considerados em uma proposta avaliativa dessa natureza, constituindo-se em desafios para futuras avaliações.

A partir dos quadros organizadores do corpo de análise dos dados, pode-se dizer que a maioria dos tutores participantes da pesquisa avaliou que acredita seguir a proposta pedagógica do Curso em sua atuação. Entretanto, salienta-se que essa proposta é modificada e complementada na prática tutorial e, portanto, não se resume ao exposto no Guia do Tutor (2006) nem o abrange totalmente. Tendo em vista o que foi apontado pelos tutores, evidenciou-se que alguns deles não seguem completamente a proposta do Curso, pois há diversos aspectos que podem estar implicados em sua atuação: a) a especificidade da atividade exigida a cada tutor no Curso; b) as particularidades de cada pólo, interdisciplina, eixo articulador e grupos de trabalho; c) o desconhecimento ou não entendimento do que é proposto; d) a concordância ou discordância teórico-prática em relação ao que é proposto; 
e) as questões de ordem pessoal-profissional do tutor que repercutem em sua atuação no Curso; entre outros. Portanto, de acordo com os dados analisados, tem-se clareza de que a proposta de atuação tutorial apresenta algumas limitações em sua concretização, ou ainda, não está sendo realizada em sua plenitude por todos os tutores em sua atuação, mas ela consiste em um ideal a ser alcançado.

\subsection{Avaliação da atuação dos e pelos Tutores do Curso PEAD/UFRGS}

Tendo em vista a problemática levantada e os resultados dessa pesquisa, faz-se necessário tecer algumas palavras sobre a proposta avaliativa do Curso PEAD/UFRGS. De acordo com o Guia do Tutor, a avaliação no Curso é entendida como um processo continuado, no qual os sujeitos deverão ser permanentemente acompanhados, pois se pressupõe que "observar os avanços e as limitações de idéias, proposições e ações, próprias ou do grupo, é o fundamento para qualificar o trabalho do ser professor" - aqui também se pode estender para o ser tutor (2006: 43-44). Conforme o apresentado no referido Guia, esse processo consiste em "dinamizar oportunidades de ação-reflexão-ação no que se refere à prática docente - também podemos incluir, à prática tutorial - e aos conhecimentos adquiridos, possibilitadas pelo acompanhamento permanente (...)" (ibidem).

O processo de auto-avaliação é relevante em si mesmo, pois permite a cada tutor realizar uma revisão sobre sua própria ação e intervenção e, em conseqüência, pode ajudá-lo a adquirir maior 'competência' profissional, revertendo, provavelmente, em um benefício imediato para os alunos e a instituição. Ainda que não exista na realidade educativa uma acentuada cultura de auto-avaliação, é sumamente importante recomendar esta prática para a melhora contínua pessoal e institucional. Diante disso, segundo Gelatti, a formação continuada é imprescindível a um profissional que deseja "ser capaz de utilizar-se da mesma linguagem de seu aluno para se fazer entender", ou ainda, a quem pretende se atualizar e obter "condições de compreender as necessidades atuais dos educandos", sendo que essa formação deve ser entendida como "a educação que se renova, adequando o exercício da docência às exigências de um mundo que se transforma a cada instante" (2005: 138-139). 
Tendo em vista os dados coletados e analisados, percebe-se que a ação do tutor no Curso PEAD/UFRGS constitui um fator fundamental para a qualidade dos processos de ensino e de aprendizagem, sem desmerecer a importância da auto-gestão que caracteriza o perfil do aluno que se deseja, seja ele proveniente de um curso a distância ou de um presencial. Corresponde ao tutor, como apoio docente, a atribuição de fomentar a aprendizagem para concretizar os objetivos propostos através da ativação dos processos cognitivos, sociais, afetivos, além de avaliar os processos realizados e a concretização dos mesmos para o re-direcionamento de concepções e práticas. Isso supõe colocar em prática as variadas 'competências' próprias de sua função - evidenciadas pelo Curso PEAD/UFRGS nas categorias e indicadores levantados - que permitam ao tutor atuar coerentemente, nos âmbitos virtuais e presenciais, quanto ao atendimento dos alunos; à fluência na telemática/ tecnologia e à prática das concepções e metodologias do Curso PEAD.

Resulta, portanto, a relevância de assegurar a melhora contínua das mencionadas 'competências'. A prática da auto-avaliação do desempenho realizado pelo tutor constitui em um instrumento essencial para proporcionar essa melhora. No sentido formativo, a auto-avaliação fundamenta-se em um incentivo à confrontação da 'auto-imagem', a qual o tutor tem de si com o ideal declarado para o cumprimento de sua função. Os resultados desta confrontação possivelmente não são suficientes se o tutor não conta com suportes de apoio para superar suas dificuldades, orientadas pelos critérios de praticidade, flexibilidade e adaptabilidade às necessidades encontradas para o melhor exercício da profissão.

Observa-se, pelos dados analisados, que, em geral, cada nova interdisciplina e/ou etapa do Curso oportuniza ao tutor oportunidades de aperfeiçoamento de sua atuação, para o qual é preciso uma avaliação sistemática e contínua de sua prática na ação tutorial, um crescente domínio de 'competências', entre outros. É ainda significativo acrescentar que

para que a avaliação da aprendizagem seja satisfatória, é necessário que o educador [também podemos considerar o tutor, na avaliação de sua própria atuação] a conceba como práxis pedagógica, utilizando instrumentos diversificados para ela e transformando o ato avaliativo em vivência prazerosa de descoberta e troca de conhecimentos (Santos, 2004: 78). 
O instrumento de auto-avaliação, bem como a apresentação dos dados encontrados pretendeu potencializar, ao tutor, a tarefa de reflexão, permitindo análise e auto-avaliação do realizado, nas diferentes dimensões de sua atuação. A aplicação das categorias e de seus respectivos indicadores poderá permanecer como um diálogo interior, um documento reflexivo, capaz de explicitar as inovações que foram introduzidas à concretização do projeto de aprimoramento contínuo da práxis educativa.

\section{Considerações finais}

O fato de se constituírem numa equipe de tutores adultos e de profissionais no mínimo graduados não os exime, de maneira alguma, de novas aprendizagens, inclusive da formação de valores, atitudes de compreensão, constância, progresso e intensificação de interações, com o objetivo de solidificar a aprendizagem. Estes aspectos deverão ser levados em consideração na função da tutoria, segundo os sujeitos participantes dessa pesquisa, para potencializar as oportunidades no desenvolvimento cognitivo/social/afetivo.

Portanto, com o instrumento avaliativo aplicado foi possível analisar que os tutores puderam refletir sobre suas práticas pedagógicas através da descrição e avaliação da própria atuação, com a apresentação de aspectos vividos e/ou praticados com maior aproximação do real, estruturando estratégias fomentadoras da construção da aprendizagem dos alunos, bem como contribuindo com aspectos que podem qualificar a atuação de todos os partícipes do Curso.

O processo de (auto)avaliação proposto pelo Curso, relatado e discutido nesse artigo, ofereceu uma oportunidade para o tutor avaliar a sua atuação e para os demais partícipes do Curso - coordenações, professores, tutores, etc. - apropriarem-se dos resultados deste processo, intencionando que os relatos avaliativos dos tutores possam contribuir efetivamente para o aperfeiçoamento da tutoria e do Curso em sua totalidade. Para a compreensão e efetivo exercício da avaliação como processo, é fundamental o investimento em novas reflexões e movimentos por parte dos partícipes do Curso em prol de uma cultura de participação em todas suas instâncias (Gelatti, 2005: 80). 
A avaliação nesta perspectiva significa abrir espaços de reflexão crítica por parte do tutor (bem como dos demais partícipes) sobre sua própria intervenção, para visualizar processualmente os sucessos/acertos e as dificuldades, para que estas últimas possam ser transformadas positivamente, como conseqüência do processo de auto-análise. Trata-se de oportunizar espaços para a auto-reflexão e de meta-reflexão, de exame contínuo da prática e das teorias que a subsidiam, de reconhecimento do próprio nível de satisfação alcançado, a fim de utilizar os dados levantados por meio desse processo auto-avaliativo, bem como a análise destes dados, para conseguir oportunas transformações qualificadas da ação tutorial.

Finalmente, convém salientar nesse âmbito que a auto-avaliação somente terá sentido se houver, quando necessário, uma mudança das práticas do tutor. Será importante prever mecanismos concretos para que os resultados obtidos por meio do processo avaliativo contribuam na formação contínua da tutoria e na melhora da proposta pedagógica do Curso, do projeto acadêmico e/ou da instituição, como, por exemplo, por meio da promoção de reuniões com os tutores, coordenações e/ou membros da equipe docente, da assistência a interdisciplinas e equipes de trabalho do Curso de acordo com as necessidades de formação evidenciadas. Trata-se, dessa forma, de assegurar o qualitativo feedback da avaliação realizada.

\section{Notas}

1 Originou-se do trabalho proposto nas disciplinas Tutoria em Educação a Distância I e Tutoria em Educação a Distância II, ministradas pelas Professoras Dras. Rosane Aragon de Nevado (Coordenadora Geral do Curso PEAD) e Marie Jane Carvalho (Vice-Coordenadora do Curso PEAD), pelos Programas de Pós-Graduação em Educação (PPGEDU) e em Informática na Educação (PPGIE) da UFRGS.

2 O site do PBWIKI é http://www.pbwiki.com; o do WIKI do PEAD é http://www.pead.pbwiki.com.

3 Diário de Bordo é uma ferramenta que possibilita ao usuário o registro pessoal de construções, aprendizagens, reflexões, inquietudes, etc., permitindo, no âmbito educacional, o acompanhamento avaliativo processual e a intervenção pedagógica do professor e do tutor em relação aos registros efetuados pelos alunos.

4 Ambiente virtual disponível no site http://www.ead.ufrgs.br/rooda (somente para usuários cadastrados) e no site do ROODA em http://rooda.edu.ufrgs.br. 
5 O Webfólio é uma das ferramentas mais utilizadas pelo professor e tutor para o acompanhamento avaliativo das produções do aluno e intervenção pedagógica no Curso PEAD/UFRGS.

6 A2 é uma ferramenta de comunicação síncrona on-line entre usuários conectados no ROODA.

\section{Referências}

ARETIO, Lorenzo García (1999). A Perspectiva Teórica do Ensino Aberto a Distância e a Televisão. Secretaria de Educação a Distância. Brasília: Ministério da Educação, SEED.

BARDIN, Laurance (1977). Análise de Conteúdo. Lisboa: Edições 70.

BEN, Vânia (2004). Interação usuário-hipertexto em curso on-line. In VI CONGRESO DE LINGÜÍSTICA GENERAL, 5., Universidad de Santiago de Compostela.

BOFF, Leonardo (1998). O Despertar da Águia: o Dia-bólico e o Sim-bólico na Construção da Realidade. Petrópolis: Vozes.

BERTRAND, Yves \& VALOIS, Paul [s.d.]. Paradigmas Educacionais, Escola e Sociedade. Lisboa: Ed. Piaget.

BRASIL. MEC. SEED (2008). Decreto № 5.622, de 19 de dezembro de 2005. [Em linha] [Acedido em 30 de Junho de 2009, disponível em: <http://www.planalto.gov.br/ ccivil_03/_Ato2004-2006/2005/Decreto/D5622.htm.

CARVALHO, Marie Jane; NEVADO, Rosane Aragon \& BORDAS, Mérion Campos (2006). Guia do Tutor. Curso de Licenciatura em Pedagogia a Distância: Anos Iniciais do Ensino Fundamental. Porto Alegre: Faculdade de Educação (FACED).

CRUZ, Dulce Márcia (2001). O professor midiático: a formação docente para a educação a distância no ambiente virtual da videoconferência. Tese (Doutorado em Engenharia de Produção). Florianópolis: Universidade Federal de Santa Catarina.

FILHO, Roberto Fragale (Org.) (2003). Educação a Distância: Análise dos Parâmetros Legais e Normativos. Rio de Janeiro: DP\&A.

FREIRE, Paulo \& FAUNDEZ, Antonio. (1985). Por uma Pedagogia da Pergunta. Rio de Janeiro: Paz e Terra.

GADOTTI, Moacir \& ROMÃO, José E. (Orgs.) (2003). Educação de Jovens e Adultos: Teoria, Prática e Proposta. 6.ed. São Paulo: Cortez/Instituto Paulo Freire.

GELATTI, Lilian Schwab (2007). A Formação de Professores para a Apropriação da Educação a Distância: Caminhos, Rupturas e Desafios. Anteprojeto (Doutorado em Educação). Programa de Pós-Graduação em Educação. Porto Alegre: Universidade Federal do Rio Grande do Sul.

GELATTI, Lilian Schwab (2005). A Formação de Educadores de Jovens e Adultos: Potencializadora e Potencializada Pela Educação a Distância? Dissertação (Mestrado em Educação), Porto Alegre: Faculdade de Educação, PUCRS. 
LÉVY, Pierre (1993). As tecnologias da Inteligência: o Futuro do Pensamento na Era da Informática. Rio de Janeiro: Editora 34.

LITWIN, Edith (Org.) (2001). Educação a Distância: Temas para o Debate de uma Nova Agenda Educativa. Porto Alegre: Artmed.

MARCHAND, Louise (2002). Características e Problemáticas e Específicas: a Formação Universitária pela Videoconferência. trad. Fátima Murad. Porto Alegre: Artmed.

MARTíNEZ, Ruben A. Lima (1998). O Planejamento Educacional no Sistema Estadual de Educação (SEC) no Rio Grande do Sul. Tese (Doutorado). Salamanca: Universidad Pontificia de Salamanca.

MOORE, Michael G. \& KEARSLEY, Greg (2008). Educação a Distância: uma Visão Integrada. trad. Roberto Galman. São Paulo: Cengage Learning.

MORAES, Roque de \& LIMA, Valderez Marina do Rosário (Orgs.) (2002). Pesquisa em Sala de Aula: Tendências para a Educação em Novos Tempos. Porto Alegre: EDIPUCRS.

MORAN, José Manuel (2000). Tecnologias para uma nova educação. Comunicação pessoal.

MORIN, Edgar (2001). Os Sete Saberes Necessários para Ensinar. Trad. Catarina Elconora F. Silva e Jeanne Sawaya. São Paulo: Cortez.

PALLOFF, Rena M. \& PRATT, Keith (2002). Construindo Comunidades Virtuais de Aprendizagens no Ciberespaço. Porto Alegre: Artmed.

PERKINS, Jorge Eduardo Padula. (2003). Una Introducción a la Educación a la Distancia. Buenos Aires: Fondo de Cultura Economica de Argentina.

PIAGET, Jean (1995). Abstração Reflexionante: Relações Lógico-aritméticas e Ordem das Relações Espaciais. Porto Alegre: Artes Médicas.

RAUEN, Fábio José (2002). Roteiro de Investigação Científica. Tubarão: Editora Unisul.

SOUZA SANTOS, Boaventura (2000). A Crítica da Razão Indolente: Contra o Desperdício da Experiência. São Paulo: Cortez.

SOUZA SANTOS, Boaventura de Souza (2005). A Universidade no Século XXI: para uma Reforma Democrática e Emancipatória da Universidade. São Paulo: Cortez.

TARDIF, Maurice; LESSARD, Claude. (2008). O Ofício de Professor: História, Perspectivas e Desafios Internacionais. trad. Lucy Magalhães. Petrópolis, RJ: Vozes. 
THE SELF-EVALUATION OF TUTORS' FUNCTION AT THE UNDERGRADUATION COURSE IN DISTANCE PEDAGOGY OF A BRAZILIAN UNIVERSITY

\section{Abstract}

This article describes and analyses the self-evaluation of Tutors' function at the Undergraduation Course in Distance Pedagogy - PEAD/UFRGS, offered by a Brazilian University. We intended to test, through a study case, the tutors' performance at this distance course environment, accordingly to the tutors' guide, and to assess if such procedures enable a better learning.

Keywords

Tutorship; Distance education; Evaluation

\section{AUTO-EVALUACIÓN DE LA FUNCIÓN DE LA TUTORÍA EN EL CURSO DE GRADUACIÓN EN PEDAGOGÍA A LA DISTANCIA DE UNA UNIVERSIDAD BRASILEÑA}

Resumen

Este artículo tiene como objetivo relatar y analizar la auto-evaluación de la función de la Tutoría en el Curso de Graduación en Pedagogía a la Distancia - PEAD/UFRGS, ofrecido por una universidad brasileña. Con el intuito de sondear la función de los tutores en este curso a la distancia, fue utilizado el estudio de caso, en conformidad con la Guía del Tutor, y percibir si tales procedimientos posibilitan mejores aprendizajes

Palabras-clave

Tutoría; Educación a la distancia; Evaluación 